\title{
A rede social e os tipos de apoio recebidos por idosos institucionalizados
}

\author{
The social network and types of support received by the institutionalized elderly
}

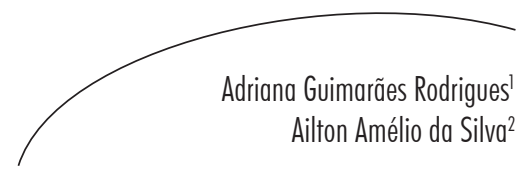

\section{Resumo}

Estudo descritivo que teve como objetivo identificar a composição da rede de apoio social de idosos institucionalizados, bem como os tipos e as quantidades de apoios recebidos por eles. $\mathrm{O}$ apoio social tem função importante no enfretamento das perdas e limitações da velhice. Participaram 30 idosos institucionalizados com média de idade de 74 anos. Foram aplicadas entrevistas e a escala de apoio social para identificar a composição da rede social e tipos de apoio social que os idosos recebiam. A rede social desses idosos era composta, em ordem decrescente de quantidade, por familiares, amigos, internos e funcionários da instituição. Embora esses idosos possuíssem familiares vivos, 29 deles recebiam mais apoio social dos amigos do que de seus familiares. Somente 13 recebiam apoio de poucos familiares (em média 1,8 membros da família ofereciam apoio aos idosos), sugerindo a existência de comprometimentos na relação desses idosos com os familiares. Os idosos recebiam apoio material, afetivo e emocional quase sempre e apoios de informação e de interação social positiva, às vezes. A conclusão, pelos resultados, é que os idosos recebiam apoio de poucas pessoas de suas redes sociais.

\section{Abstract}

This is a descriptive study which aimed at identifying the composition of social support networks of the institutionalized elderly, as well as the types and quantity of support received. The social support network has an important role when dealing with the losses and limitations of old age. Thirty institutionalized elderly (with a median age of 74) participated in the study. To identify the composition of social support and types of support received by the institutionalized elderly, interviews and a social support scale were applied. The social support network of the

\section{Palavras-chave:}

Envelhecimento. Instituição de Longa Permanência para Idosos. Idoso. Rede Social. Apoio Social.

\footnotetext{
Departamento de Psicologia. Pontifícia Universidade Católica de Minas Gerais. Arcos, MG, Brasil.

2 Programa de Pós-graduação em Psicologia Experimental, Instituto de Psicologia. Universidade de São Paulo. São Paulo, SP, Brasil.
} 
institutionalized elderly was composed in descending order of the quantity of support received from: acquaintances, friends, the other institutionalized and the workers of the institution. Even though the institutionalized elderly had living acquaintances, 29 received more support from friends than from their acquaintances. Only 13 of the elderly received support from few acquaintances (in median 1.8 members of the family offered support to the institutionalized elderly), suggesting an existence of a weak relationship between the institutionalized elderly and their acquaintances. The institutionalized elderly almost always received material, affectionate and emotional support and at times they received informational and interactive positive social support. The outcomes yielded evidence that the institutionalized elderly received support from few people and their social networks.
Key words: Aging. Homes for the Aged. Aged. Social Networking. Social Support.

\section{INTRODUÇÃO}

O rápido envelhecimento populacional e suas consequências parecem estimular o desenvolvimento de estudos sobre esta etapa do ciclo vital, mas os resultados desses estudos ainda não são suficientes para instruir a tomada de medidas eficientes em diversas áreas que favoreçam melhorias na qualidade de vida na velhice, principalmente a de idosos institucionalizados. ${ }^{1}$ As dificuldades de atender às necessidades dos idosos se refletem na crescente demanda pela institucionalização de idosos em instituições de longa permanência para idosos (ILPIs). ${ }^{2,3}$

Considerando as estimativas estatísticas sobre o envelhecimento populacional do Brasil e o aumento da expectativa de vida, acredita-se que a demanda pela institucionalização dos idosos tende a aumentar nas próximas décadas. ${ }^{4,5}$ Estas projeções evidenciam a urgente necessidade de se investir em estudos capazes de indicar as condições de vida com mais qualidade para os idosos institucionalizados.

As ILPIs funcionam como organizações sociais regulamentadas pelo governo com atividades dirigidas por regimento e que assumem um caráter asilar por tutelarem os idosos. No Brasil, há um predomínio de ILPIs de cunho assistencial e filantrópico. Boa parte dessas instituições ainda não possui número suficiente de profissionais qualificados para cuidar dos idosos. ${ }^{6}$
Existem também as ILPIs privadas, conhecidas como casas geriátricas, hotel residência para idosos e outras. O número de ILPIs de caráter privado e com fins lucrativos aumentou consideravelmente nas últimas décadas, e o padrão de seus serviços é bastante heterogêneo. ${ }^{7}$ Nessas instituições, a prestação de serviços costuma ser mais adequada ao perfil do idoso., ${ }^{7,8}$

Atualmente, muitas ILPIs brasileiras passaram ou estão passando por modificações substanciais, com a organização das equipes multiprofissionais adequadas para oferecer cuidados mais especializados, melhor acessibilidade da estrutura física e outras modificações. Essas modificações têm ocorrido de forma lenta, perpetuando a imagem negativa do modelo asilar segregador., ${ }^{910}$

A institucionalização de idosos ocorre em função de vários motivos, dentre eles, pela diminuição da rede de apoio social. ${ }^{11} \mathrm{O}$ afastamento dos filhos para constituírem suas famílias, a morte de parentes e amigos e outros fatores fazem com que, gradativamente, a rede social dos idosos diminua, tornando-os mais vulneráveis ao desamparo. Ademais, com a institucionalização e o afastamento dos poucos amigos e membros familiares, a rede de apoio do idoso torna-se ainda mais fragilizada e escassa.

\section{As redes de apoio social}

O interesse pelos estudos científicos sobre os impactos das redes de apoio social sobre a saúde 
e bem-estar das pessoas é recente e foi iniciado com os estudos de Cobb $^{12}$ e Cassel. ${ }^{13}$ Esses autores conseguiram compilar evidências que demonstram que a suscetibilidade às doenças fica aumentada com a ruptura dos laços sociais.

Existem poucos estudos publicados, no Brasil, sobre a função do apoio social para os idosos institucionalizados. Essa situação desencadeia vários questionamentos pela importância que $\mathrm{o}$ apoio social tem na qualidade de vida dos idosos e pela baixa produção científica sobre o assunto. ${ }^{11}$

É importante diferenciar apoio social de interação social, pois nem toda interação social oferece apoio. Algumas interações sociais podem ser, até mesmo, muito negativas e estressantes, como nos casos em que os filhos superprotegem os pais idosos ou fazem cobranças excessivas de desempenho social e em outras situações. ${ }^{11}$ É importante, também, distinguir rede social de apoio social. O termo "rede social" é utilizado por diversos autores para referenciar um grupo de pessoas que apresentam alguma forma de contato entre elas. ${ }^{14,15}$

O apoio social ocorre em um processo dinâmico e complexo que engloba a interação do indivíduo com sua rede social e as trocas estabelecidas entre eles. Por meio dessas interações, o indivíduo pode satisfazer parte de suas necessidades sociais. ${ }^{16,17}$

O conceito de apoio social abrange aspectos estruturais, funcionais e contextuais. Os aspectos estruturais envolvem o tamanho e a composição das redes sociais que oferecem apoio. Os aspectos funcionais referem-se às funções que o apoio exerce na vida do indivíduo que recebe e que fornece apoio social. Por sua vez, os aspectos contextuais referem-se à adequabilidade do apoio social à situação em que o indivíduo está vivendo. ${ }^{14,18}$

As redes de apoio social também podem ser consideradas em suas simetrias, estabilidades, conectividades e homogeneidades, bem como em relação às características e frequências das interações entre seus membros e os tipos de apoio fornecidos e recebidos. A relação entre as pessoas, que trocam apoio social, costuma ser hierarquizada, sendo algumas relações mais íntimas do que as outras. Nas relações mais íntimas, o indivíduo é mais amparado, acolhido em suas dificuldades e recebe auxílio para interpretar suas experiências e afirmar seus valores. Essas relações funcionam como amortecedores para os eventos negativos e contribuem para o aumento do bemestar subjetivo do indivíduo. ${ }^{19}$

Outro aspecto relevante refere-se ao modo como as pessoas percebem o apoio social recebido. É importante considerar as percepções que o indivíduo tem do apoio social e de sua disponibilidade, pois dificuldades cognitivas e afetivas podem comprometer essa percepção. Embora o apoio social dependa das funções desempenhadas por grupos ou pessoas significativas para o indivíduo, seu valor está diretamente relacionado à capacidade de este perceber o apoio social recebido. ${ }^{14}$ Essa percepção se traduz na crença de que o indivíduo é estimado e de que as pessoas se interessam por ele, estando disponíveis quando ele precisar. ${ }^{16}$

No Brasil, os estudos que abordam essa temática na velhice, têm, como marco, as pesquisas da professora Dra. Anita Liberalesso Neri. Seus estudos demonstram que idosos com vida social intensa, aumentam o tempo e a qualidade de vida. ${ }^{20}$

\section{As redes de apoio social de idosos}

As relações sociais são mobilizadas de acordo com cada contexto específico e estruturam os comportamentos cotidianos das pessoas, favorecendo suas integrações sociais. As redes de apoio social para os idosos têm uma função primordial quando contribuem para que eles se sintam queridos, valorizados e tenham o sentimento de pertença a um grupo. Assim, diminuem-se os sentimentos de solidão, isolamento e anonimato. ${ }^{14}$

O grau de satisfação com que uma pessoa idosa encara a vida também resulta da 
representação que ela faz de sua vida passada, de sua condição atual e da perspectiva de seu futuro, principalmente, se conseguiu ou não atingir os objetivos que havia traçado em sua vida. $\mathrm{O}$ grau de satisfação com a vida, portanto, resulta de inúmeros fatores externos e internos. Dentre estes, um dos mais importantes é o êxito do seu processo adaptativo contínuo em enfrentar as inúmeras transformações que se sucedem. ${ }^{21}$

Para o idoso, a qualidade de vida é afetada pelas perdas e carências, mas o efeito perturbador delas depende muito do significado que ele lhes atribui. Esse significado, por sua vez, é dependente da crença de autoeficácia do idoso e do quanto ele se percebe estimado por outras pessoas. Neste sentido, o apoio social recebido contribui decisivamente para o bem-estar e qualidade de vida do idoso. ${ }^{21,11}$

A manutenção de relações sociais com cônjuge, familiares e amigos da mesma geração favorece o bem-estar psicológico e social dos idosos. As mulheres, por serem mais calorosas e capazes de estabelecer relações de intimidade, apresentam redes de relações sociais mais desenvolvidas. ${ }^{20}$

A ausência de parentes mais próximos, como cônjuges ou filhos, está associada à doença e à mortalidade. ${ }^{1}$ Idosos solteiros, viúvos, separados e sem filhos são os que recebem menos apoio social e têm uma qualidade de vida mais comprometida. ${ }^{1}$ Dados de pesquisas têm demonstrado que os homens buscam e encontram apoio social em suas companheiras, mas as mulheres não encontram a mesma reciprocidade em seus companheiros. ${ }^{1,20}$ Tal discrepância pode ser explicada pelas diferenças de papéis sociais e hierarquia entre homens e mulheres. ${ }^{1,20}$

Um estudo sobre o apoio social e a saúde dos idosos demonstrou que o apoio social pode tanto estar associado a resultados favoráveis como a desfavoráveis nos níveis de saúde dos idosos, porém as evidências que indicam a existência de resultados favoráveis têm sido predominantes. ${ }^{1} \mathrm{O}$ apoio social auxilia no enfrentamento das perdas e limitações decorrentes do processo de envelhecimento e, para os idosos institucionalizados, também ajuda no enfrentamento dos problemas decorrentes da institucionalização.

O presente estudo objetivou identificar como é composta a rede de apoio social de idosos institucionalizados e o tipo e a quantidade de apoio social que recebem.

\section{METODOLOGIA}

Pesquisa descritiva do tipo survey que teve como objetivo identificar como é composta a rede de apoio social de 30 idosos institucionalizados e os tipos e as quantidades de apoio social que eles relataram receber.

\section{Participantes}

Todo o processo da pesquisa ocorreu em conformidade com os princípios éticos estabelecidos na Resolução no 196/96, do Conselho Nacional de Saúde. A coleta dos dados ocorreu somente após a aprovação do Comitê de Ética em Pesquisa com Seres Humanos do Instituto de Psicologia da Universidade de São Paulo (protocolo $\mathrm{n}^{\circ}$ 2009.077), a anuência da direção das ILPIs e a assinatura do Termo de Consentimento Livre e Esclarecido de cada idoso participante. A pesquisa foi desenvolvida no segundo semestre de 2010, em três ILPIs filantrópicas de três cidades do interior de Minas Gerais, próximas umas das outras num raio de $120 \mathrm{~km}$. Essas ILPIs foram escolhidas pela facilidade de acesso do pesquisador.

$\mathrm{Na}$ escolha dos participantes, foram selecionados todos os idosos da instituição, com idades acima de 60 anos, sem restrição quanto ao sexo, renda, escolaridade e etnia. Esses idosos, no entanto, não poderiam apresentar comprometimento cognitivo e/ou auditivo que os impossibilitassem de entender os objetivos da pesquisa, o modo de participação e de responder aos instrumentos de coleta de dados. Dentre aqueles que atenderam aos critérios, foram sorteados dez idosos de cada instituição. 
Instrumentos

\section{I- Entrevista semiestruturada}

Para obtenção de dados dos participantes e de suas redes sociais de apoio. Os dados obtidos referiam-se à idade dos participantes, à escolaridade, à situação profissional atual e anterior, ao tempo de institucionalização, aos problemas de saúde, à periodicidade das visitas recebidas, à presença de familiares vivos, as amizades, as ajudas recebidas e a outras.

\section{II- Escala de apoio social}

É um instrumento de medida autoinforme composto por 19 itens que avaliam cinco dimensões funcionais de apoio social, sendo eles: 1) material: composto por quatro perguntas sobre provisão de recursos práticos e ajuda material; 2) afetivo: composto por três perguntas sobre demonstrações físicas de afeto e amor; 3) emocional: composto por quatro perguntas que envolvem expressões de compreensão, afeto positivo e sentimentos de confiança; 4) interação social positiva: composto por quatro perguntas sobre a disponibilidade de pessoas para se divertir e relaxar juntas; e 5) informação: composto por quatro perguntas sobre a disponibilidade de pessoas para a obtenção de conselhos ou orientações. Em seguida, a cada uma das perguntas, existia uma escala do tipo likert, graduada da seguinte forma: 1- nunca, 2- raramente, 3- às vezes, 4- quase sempre e 5sempre. ${ }^{17,22}$

\section{Procedimentos}

Inicialmente, foram feitos contatos com as diretorias das ILPIs para explicação dos objetivos da pesquisa, metodologia utilizada, seleção dos idosos, modo de participação destes, consentimento livre e esclarecido dos participantes, anonimato da identidade deles e outras informações.
Os 30 idosos selecionados foram convidados a participar da pesquisa, esclarecidos sobre os seus objetivos e de seu modo de participação. Inicialmente, foi realizada a entrevista e, em outro dia, a aplicação da escala de apoio social. A entrevista e a aplicação da escala de apoio social ocorreram, individualmente, em uma sala das ILPIs.

Os resultados coletados foram analisados quantitativamente por meio de estatística descritiva, utilizando-se os recursos do programa Microsoft Office Excel 2007 e a análise de variância (One-Way ANOVA com pós-teste de Bonferroni) do programa GraphPad Prism 5.0.

\section{RESULTADOS}

Os idosos possuíam em ordem crescente de quantidade: parentes, amigos de fora da instituição, internos e funcionários da instituição em suas redes sociais. Dos 30 idosos que participaram da pesquisa, 17 eram do sexo feminino e 13, masculino. Quanto ao estado civil, 18 eram solteiros, oito viúvos, um casado e três divorciados.

A média de idade dos idosos era de 74 anos (dp: 9,1 anos). Quanto à escolaridade, três eram analfabetos, 15 não completaram a $4^{a}$ série do ensino fundamental e 12 completaram somente a $4^{a}$ série. Com relação à fonte de renda, todos os idosos eram aposentados e/ou pensionistas.

O tempo médio de institucionalização dos idosos era de seis anos e cinco meses (dp: 7,5 anos), variando entre um mês a 34 anos de institucionalização. Segundo seus relatos, 16 idosos foram institucionalizados por um membro da família, seis por amigos, seis foram encaminhados pelo serviço de assistência social do município ou por ordem judicial e dois pelos seus ex-patrões.

Os motivos da institucionalização apontados por eles foram: seis idosos não tinham onde morar; 10 já moravam sozinhos e não tinham mais condições físicas e/ou financeiras de 
continuar assim e 14 disseram que a família não queria e/ou poderia cuidar deles.

Dos 30 idosos entrevistados, 29 relataram possuir familiares vivos (em média, 7,8 parentes), sendo a maioria composta por irmãos e sobrinhos; um idoso era casado, oito tinham filhos e dois, enteados, entretanto somente 24 idosos tinham contato com os familiares.

A frequência de contato entre os idosos e seus familiares, de acordo com seus relatos, era variável: seis idosos relataram ter contato com os familiares uma vez por semana; nove, uma vez por mês; cinco, algumas vezes por ano; quatro, anualmente; um, em intervalos maiores do que um ano e cinco, não tem mais contato com os familiares. A baixa frequência de contato ou o não-contato não decorria da distância física entre a instituição asilar e o local em que os familiares moravam, pois os familiares de 28 idosos moravam nas mesmas cidades onde se encontravam as instituições nas quais esta pesquisa foi realizada, sendo essas cidades de pequeno porte.

Para os 24 idosos que tinham contato com os familiares, o relacionamento, com pelo menos um dos parentes, foi avaliado como bom, porém somente 13 idosos relataram receber algum tipo de apoio dos familiares, como ajuda material, afetiva, emocional, interação social positiva e o fornecimento de informações.

Os idosos entrevistados não possuíam um alto grau de dependência. Ao contrário, esses idosos eram bastante independentes e autônomos, e, inclusive, nove deles ajudavam nas atividades da instituição como auxiliares de cozinha, de limpeza e no cuidado de outros idosos.

Sobre as relações de amizade com pessoas de fora da instituição, 24 idosos (14 idosas e 10 idosos) tinham, em média, três amigos cada. Dentre os amigos citados, 59\% eram do sexo feminino e $41 \%$ do sexo masculino. Idosas tinham mais amigas do sexo feminino $(76 \%)$ e idosos, mais amigos do sexo masculino (90\%). Setenta e cinco por cento das 71 amizades relatadas pelos 24 idosos foram constituídas há mais de 10 anos.

A frequência de contato entre eles e os amigos era, na maioria das vezes, mensal. Todos os idosos, que tinham amigos de fora da instituição, disseram que o relacionamento com eles era bom. Além disso, 20 dos 24 idosos, que tinham amigos de fora da instituição, relataram receber ajuda deles.

Com relação ao desenvolvimento da amizade nas ILPIs, 23 idosos (12 idosas e 11 idosos) relataram que construíram laços de amizade dentro da instituição (em média 2,4 amigos por idoso). Idosas tinham mais amigas (88\%); e idosos, mais amigos (80\%). Isso sugere que os papéis de gênero têm um peso razoável sobre suas escolhas. De acordo com o relato de alguns idosos participantes da pesquisa, a busca de contato com um idoso do outro sexo pode significar interesse amoroso.

Diferentemente dos amigos de fora da instituição, o tempo de relacionamento com a maioria dos amigos de dentro da instituição era bem menor. A amizade com 57\% dos amigos institucionalizados foi constituída em menos de dois anos.

Dentre os amigos da instituição, 59\% eram internos e 43\% funcionários. Somente 23 idosos fizeram relações de amizade na instituição e, ainda assim, sete deles fizeram amizade, exclusivamente, com funcionários. Em média, os idosos tinham 1,4 amigos que eram internos da instituição. Os 23 idosos avaliaram o relacionamento com os amigos da instituição como bom e 20 disseram que recebem ajuda deles.

Apesar de os idosos possuírem, em média, 7,8 parentes vivos, três amigos de fora da instituição e 2,4 amigos que eram internos e funcionários da instituição eles não recebiam apoio social de todos os parentes e amigos de sua rede social, como poderá ser visto nas figuras 1 e 2 . A figura 1 apresenta dados das 17 idosas e a figura 2 dos 13 idosos. 


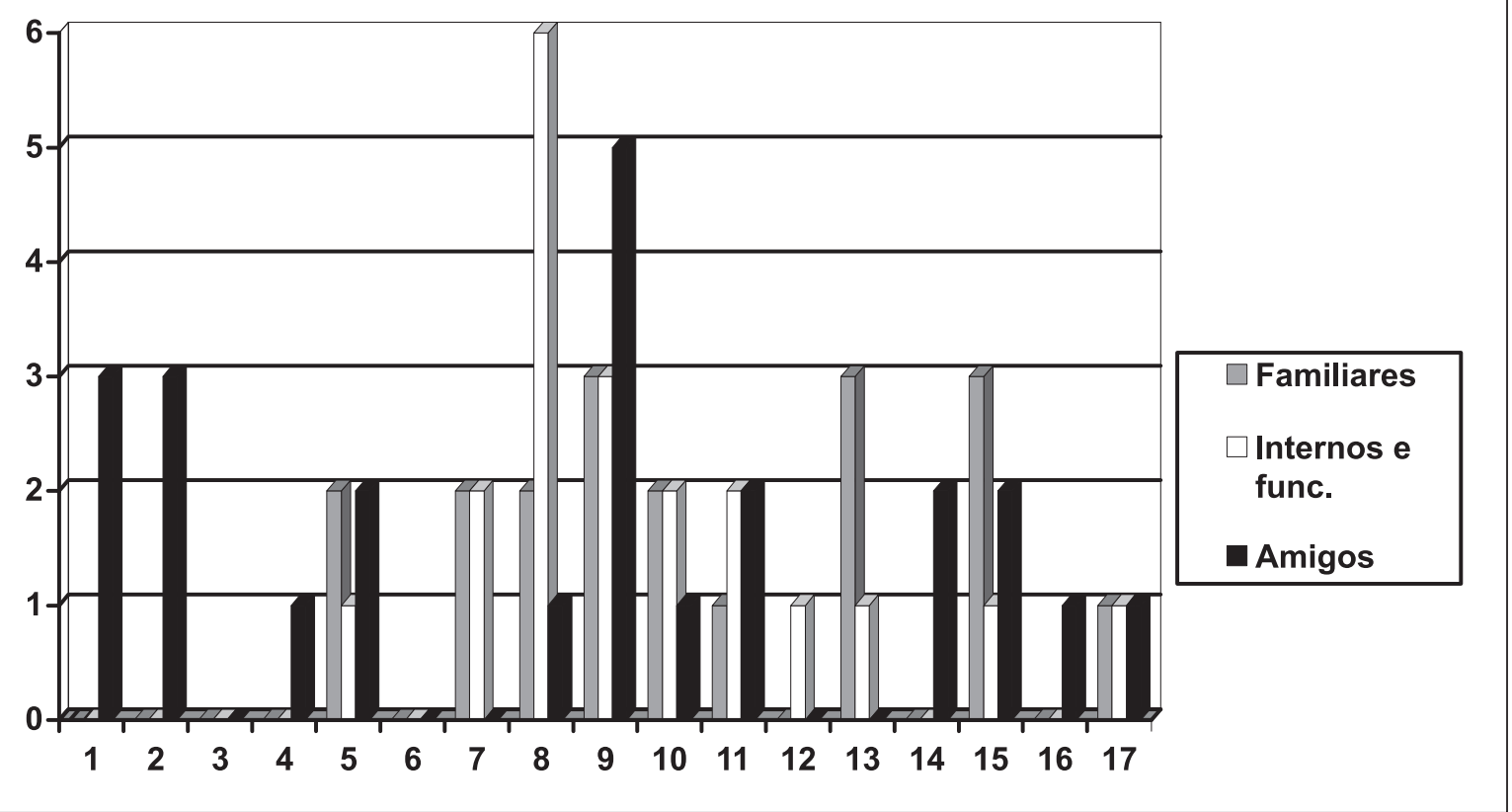

Figura 1 - Quantidade de pessoas da rede social que forneciam apoio para as 17 idosas. Arcos, MG, 2010.

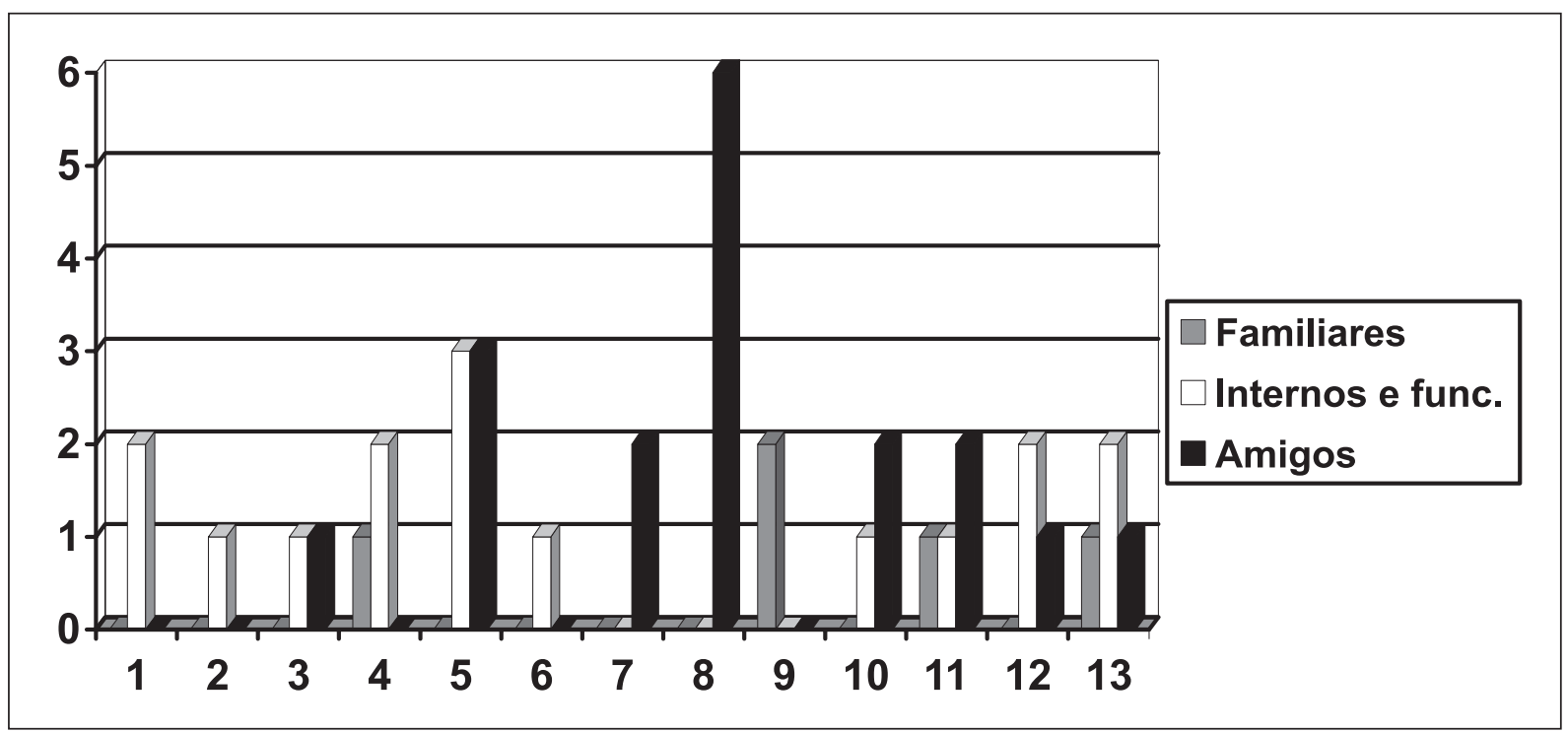

Figura 2 - Quantidade de pessoas da rede social que forneciam apoio para os 13 idosos. Arcos, MG, 2010. 
Verifica-se que nove idosas e quatro idosos relataram que recebem apoio de seus familiares. Do total de 7,8 parentes vivos, em média, 1,8 parentes forneciam apoio para eles, ou seja, $23 \%$ dos parentes relatados pelos idosos forneciam apoio, ainda assim para 13 idosos somente. Dezessete idosos não recebiam apoio de seus parentes.

Vinte idosos (10 idosas e 10 idosos) dos 23 que fizeram amizade com os demais internos e funcionários da instituição relataram receber apoio de, em média, 1,8 desses. Com relação à quantidade de amigos de fora da instituição, os quais forneciam apoio social, 20 idosos (12 idosas e 8 idosos) recebiam apoio de, em média, 2,1 amigos.

De maneira geral, os idosos recebiam apoio de, em média, 3,9 amigos de dentro e de fora da instituição e de 1,8 familiares.

Tipos e quantidade de apoio social que os idosos recebiam

A quantidade média dos apoios sociais que os idosos relataram que recebem está representada na figura 3.

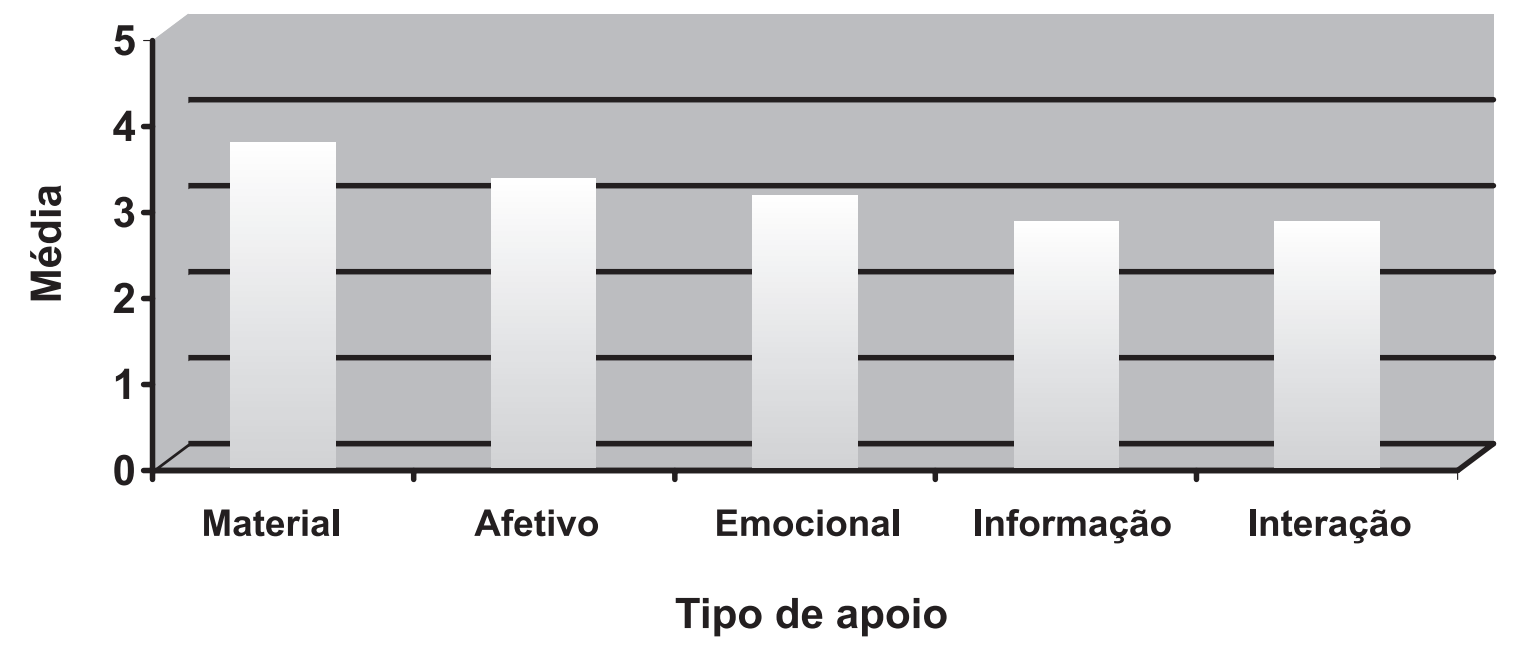

Figura 3 - Tipo e quantidade, em média, de apoio social recebido pelos 30 idosos. Arcos, MG, 2010.

Para uma melhor compreensão do significado dos escores acima, deve-se considerar que, durante a aplicação da escala de apoio social, os idosos escolhiam uma entre cinco opções da escala likert que vinha após cada pergunta do instrumento, e estas, por sua vez, foram agrupadas conforme o tipo de apoio que avaliavam. A referida escala é graduada da seguinte forma: 1) nunca; 2) raramente; 3) às vezes; 4) quase sempre; e 5) sempre.

A média geral de apoio material recebido pelos 30 idosos foi 3,8 (dp: 0,9). Essa média incide entre a opção 3 , às vezes, e a 4 , quase sempre, da escala likert do instrumento, estando mais próxima de quase sempre. $\mathrm{O}$ apoio material ocorre na forma de recursos práticos e de ajuda material para os idosos.

A média de apoio afetivo foi 3,4 (dp: 1,1) e de apoio emocional, 3,2, (dp: 1). Estes valores estão situados entre as opções "às vezes" e "quase sempre" da escala likert. O apoio afetivo ocorre por meio de demonstrações físicas de afeto e amor, e o apoio emocional, por meio de expressões de compreensão, afeto positivo e sentimentos de confiança. 
A média de apoio de interação social positiva foi 2,9 (dp: 1,2) e a média de apoio na forma de informação, 2,9 (dp: 1,1). O apoio de interação social positiva indica a disponibilidade de pessoas para situações de divertimento e relaxamento, e o apoio de informação reflete a disponibilidade de pessoas para a obtenção de conselhos ou orientações. Essas médias estão situadas entre os pontos: 2 , raramente, e 3 , às vezes, da escala likert, utilizada neste instrumento.

Esses dados indicam que os idosos recebiam apoio material quase sempre; os apoios afetivo e emocional quase sempre e às vezes, e os apoios de informação e de interação social positiva às vezes, embora as diferenças entre esses tipos de apoio não fossem estatisticamente significativas (teste estatístico - One-Way ANOVA, com pósteste de Bonferroni, $\mathrm{p}<0,05)$.

O escore de apoio material próximo de quase sempre pode ser explicado pelo fato de a instituição fornecer ajuda física e material com mais frequência, sendo esta uma de suas funções. Ademais, para muitas ILPIs, a principal forma de ajuda para os idosos é a material.

\section{DISCUSSÃO}

Foi possível perceber que a maioria dos idosos tinha familiares vivos e muitos deles possuíam parentes próximos como esposa, filhos e irmãos, entretanto não era dos familiares que os idosos recebiam mais apoio social, mas dos amigos de fora da instituição. Somente 13 idosos recebiam apoio social dos familiares, o que indica problemas relacionais, uma vez que esse tipo de apoio depende pouco de condições econômicas daqueles que podem fornecê-lo.

Esta hipótese é confirmada quando se verifica que quase metade dos idosos participantes $(47 \%)$ da pesquisa, foi institucionalizada por um membro da família, e o principal motivo alegado para a institucionalização foi o de a família não querer e/ou poder manter o idoso em casa.
A família que deveria proporcionar proteção e amparo ao idoso acaba por abandoná-lo ao institucionalizá-lo. Isso fica ainda mais evidente quando se considera que a maioria dos idosos participantes da pesquisa (exceto seis deficientes físicos, usuários de cadeira de rodas) teria condições físicas de permanecer no lar sem qualquer tipo de ajuda para realizar as atividades de vida diária. Estes idosos não requeriam cuidados físicos nem financeiros para ficarem em seus lares, visto que muitos deles eram funcionais e todos eram aposentados.

Estes dados são semelhantes aos de um estudo com 176 idosos institucionalizados da Região Nordeste do Rio Grande do Sul, no qual se verificou que grande parte dos idosos possuía família e que são os conflitos familiares os responsáveis pela institucionalização da maioria dos idosos. ${ }^{23}$ Os motivos da institucionalização de idosos, portanto, não se deve à falta de familiares para cuidar dos idosos, mas reflete as dificuldades dos familiares para cuidar de seus idosos.

A falta de motivos relacionados a doenças, a comprometimentos físicos e mentais e a problemas financeiros que justificam a institucionalização dosidosos, realça os problemas de relacionamento familiar como possível causa para essa institucionalização. De acordo com a literatura consultada, há indicações de que, para uma família institucionalizar um idoso que não seja por motivo financeiro ou pela necessidade de cuidados especializados, as relações entre eles, possivelmente, estão deterioradas. ${ }^{23-26}$

A forma como o idoso se relacionou afetiva e socialmente com seu grupo familiar ao longo de sua história de vida pode determinar o quanto ele será querido, estimado e amparado na velhice. Uma história carregada de conflitos e relações interpessoais mal resolvidas favorecem a falta de apoio e a institucionalização do idoso. ${ }^{27}$

Nãose tratadeumprocessodemãoúnica,sendo só a família responsável pelo comprometimento do vínculo com o idoso. Deve-se considerar, além das dificuldades financeiras e da aceleração 
do ritmo da vida atual os quais contribuem para que os familiares reduzam seus contatos com os idosos, a existência de algumas características comportamentais ou de personalidade do idoso que dificultam o estabelecimento e/ou o fortalecimento dos vínculos afetivos com os familiares e comprometem a relação entre eles.

A quantidade de amigos que fornece apoio social aos idosos é mais que o dobro do que a quantidade de parentes, diferentemente de idosos não institucionalizados que recebem mais apoio social de seus familiares. ${ }^{28}$

Em um estudo sobre a configuração da rede de apoio social de 300 pessoas (metade de cada sexo) pertencentes a três grupos etários, adultos jovens, adultos de meia-idade e idosos, os resultados mostraram que a rede dos idosos é composta mais por familiares. Os filhos foram apontados pelas mulheres idosas como uma importante fonte de apoio social. ${ }^{28}$

Em estudo sobre a estrutura das redes sociais e a presença de provedores de apoio social de 12 idosos com idades entre 65 e 75 anos, os resultados mostraram que as redes sociais desses idosos eram compostas por pessoas mais jovens, como os filhos, netos, genros e noras, companheiro(a) e amigos de mesmo sexo. ${ }^{29}$

Esses estudos demonstram que os idosos não-institucionalizados têm a rede social mais composta, sobretudo por familiares, dos quais eles recebem mais apoio social, diferentemente dos idosos institucionalizados participantes da presente pesquisa, os quais recebem mais apoio dos amigos.

Outro aspecto observado nesta pesquisa é que os idosos tinham poucos amigos que eram internos da instituição, média de 1,4. Embora a instituição seja um ambiente propício para o desenvolvimento de amizade, devido à proximidade física entre os idosos, pelo contato diário, pela semelhança de idade e outros, é comum observar insensibilidade e desinteresse pela construção de amizades entre eles. ${ }^{30,31}$
Estes dados estão de acordo com os resultados de uma pesquisa sobre o desenvolvimento de amizades na instituição asilar. ${ }^{31}$ Nesta pesquisa, foi possível observar que, dificilmente, a amizade espontânea ocorria entre os idosos institucionalizados, pois a maioria deles parecia não estar disposta a se deixar envolver afetivamente em uma relação de amizade com os outros idosos da instituição.

\section{CONCLUSÃO}

Esses resultados indicam que os idosos pesquisados possuem uma rede social pequena. Além disso, poucas pessoas de suas redes forneciam apoio para eles. A rede social deles era composta por familiares, amigos de fora da instituição, internos e funcionários da instituição. Os idosos recebiam bem mais apoio dos amigos do que dos familiares, diferentemente dos nãoinstitucionalizados que recebiam mais apoio de seus familiares.

Receber mais apoio dos amigos não é explicado pela falta de familiares vivos, uma vez que 29 idosos possuíam familiares vivos, sendo que a maioria dos parentes morava na mesma cidade em que estavam institucionalizados. Estes dados reforçam a hipótese de desinteresse ou existência de conflitos dos idosos com os familiares.

A pergunta que cabe aqui é: o que fazer nesta situação em que a família que poderia formar a rede social do idoso o institucionalizou e, aos poucos, vai perdendo contato com ele? $\mathrm{O}$ mesmo parece acontecer com os amigos de fora da instituição. O mais indicado seria que os idosos formassem uma rede de apoio mútuo com os demais idosos da instituição. Nessa rede, eles poderiam ser mais amparados e protegidos, além de poderem compartilhar com os demais idosos suas experiências e trocar apoio e, quem sabe, assim, eles poderiam receber apoio sempre e estariam mais fortalecidos para lutar pelos seus direitos. 
Os resultados de diversos estudos indicaram que uma boa rede de apoio social auxilia os idosos a viverem bem esta etapa da vida, minimizando os estresses decorrentes do envelhecimento. Para possuir uma boa rede de apoio social, é necessário investimento para conquistá-la e mantê-la, e as habilidades sociais possuem uma função importante neste processo. É um processo longo e bem trabalhoso, pois não se conquistam verdadeiros amigos de uma hora para outra.

$\mathrm{Na}$ institucionalização, a rede de apoio é imprescindível, pois auxilia o idoso a adaptar-se a essa situação, melhora seu bem-estar subjetivo e a qualidade de sua vida. O grande desafio é ajudar o idoso institucionalizado a estabelecer sua rede de apoio social, principalmente com os demais idosos

\section{REFERÊNCIAS}

1. Ramos MP. Apoio social e saúde entre idosos. Sociologias 2002;4(7):156-75.

2. Reis PO, Ceolim MF. O significado atribuído a "ser idoso" por trabalhadores de instituições de longa permanência: Rev Esc Enferm da USP 2007;4(1). [acesso em 6 out 2010]. Disponível: <http://dx.doi. org/10.1590/S0080-62342007000100008>.

3. Pollo SHL, Assis M. Instituições de longa permanência para idosos - ILPS: desafios e alternativas no município do Rio de Janeiro. Rev Bras Geriatr Gerontol 2008;11(1):29-44.

4. Freitas EV. Demografia e epidemiologia do envelhecimento. In: Py L, Pacheco JL, Sá JLM, Goldman SN, organizadores. Tempo de envelhecer: percursos e dimensões psicossociais. Rio de Janeiro: Nau; 2004. p. 19-38.

5. Chaimowicz F, Greco DB. Dinâmica da institucionalização de idosos em Belo Horizonte, Brasil. Rev Saúde Pública 1999;33(5):454-60.

6. Vieira EB. Manual de Gerontologia: um guia teóricoprático para profissionais, cuidadores e familiares. Rio de Janeiro: Revinter; 1996.

7. Born T. Cuidado ao idoso em instituição. In: PapaléoNetto M. organizador. Gerontologia: a velhice e o envelhecimento em visão globalizada. São Paulo: Editora Atheneu; 1996. p. 403-414. da instituição, visto que as pesquisas indicam que os idosos institucionalizados têm baixa motivação para desenvolver amizades com os demais internos da instituição, além de apresentarem atitudes preconceituosas e rejeitadoras em relação a eles. Em média, os idosos pesquisados tinham 1,4 amigos que eram internos da instituição, confirmando estas afirmações.

Novas pesquisas, portanto, devem ser feitas não só para o desenvolvimento de procedimentos e técnicas que possam melhorar as habilidades sociais dos idosos, mas para que eles sejam mais capazes de conquistar e manter uma rede social com trocas efetivas com outras pessoas, principalmente, com os demais internos da instituição. Assim, haveria benefício para todos.

8. Araujo ENP. Práticas psicogerontológicas nos cuidados de idosos. Curitiba: Juruá Editora; 2012.

9. Lafin SHF. Asilos: algumas reflexões. In: Cortelletti IA, Casara MB, Herédia VBM, organizadores. Idoso asilado: um estudo gerontológico. Caxias do Sul, RS: Educs/Edipucrs; 2004. p. 111-113.

10. Creutzberg M, Gonçalves LHT, Sobottka EA. Instituição de longa permanência para idosos: a imagem que permanece. Texto Contexto Enferm 2008;17(2):273-9.

11. Rodrigues AG. Habilidades comunicativas e a rede social de apoio de idosos institucionalizados. [tese de doutorado]. São Paulo: Instituto de Psicologia, Programa de Pós-graduação em Psicologia Experimental da Universidade de São Paulo; 2011.

12. Cobb S. Presidential Address1976. Social support as a moderator of life stress. Psychosomatic Medicine 1976;38(5):300-14.

13. Cassel J. The contribution of the social environment to host resistance: the Fourth Wade Hampton Frost Lecture. Am J Epidemiol 1976;104(2):107-23.

14. Martins RML. A relevância do apoio social na velhice. Revista do Instituto Superior Politécnico de Viseu. Millenium online [periódico na Internet]. 2005 [acesso em 22 nov 2010. Disponível em: http://www. ipv.pt/millenium/millenium31/9.pdf. 
15. Souza J. Percepção de apoio social e caracterização da rede de dependentes e não dependentes de substâncias psicoativas. [tese de doutorado]. Ribeirão Preto: Escola de Enfermagem de Ribeirão Preto da Universidade de São Paulo; 2011.

16. Mc Dowel I. Measuring health: a guide to rating scales and questionnaires. 3rd ed. New York: Oxford University Press; 2006.

17. Chor D, Griep RH, Lopes CS, Faerstein E. Medidas de rede e apoio social no estudo pró-saúde: pré-testes e estudo piloto. Cad Saúde Pública 2001;17(4):887-96.

18. Siqueira MMM. Construção e validação da Escala de Percepção de Suporte Social. Psicologia em Estudo 2008;13(2):381-8.

19. Kahn RL, Antonucci TC. Convoys over the life course: attachment, roles and social support. In: Baltes PB, Brim OG, editors. Life-span development and behavior. New York: Academic Press; 1980. p. 253-286.

20. Neri AL. Envelhecimento e qualidade de vida na mulher. Anais do $2^{\circ}$ Congresso Paulista de Geriatria e Gerontologia; 2001; Campinas. São Paulo: Universidade Estadual de Campinas; 2001. p. 1-18.

21. Barreto J. Envelhecimento e qualidade de vida: o desafio actual. Revista Faculdade Letras: Sociologia 2005;15:289-302.

22. Griep RH, Chor D, Faerstein E, Werneck GL, Lopes CS. Validade de constructo de escala de apoio social do Medical Outcomes Study adaptada para o português no Estudo Pró-Saúde. Cad Saúde Pública 2005;21(3):703-14.

23. Herédia VBM, Casara MB, Cortelletti, IA, Ramalho $\mathrm{MH}$, Sassi A. A realidade do idoso institucionalizado. Textos sobre envelhecimento 2004;7(2):9-31.

24. Herédia VBM, Cortelletti IA, Casara MB. Institucionalização do idoso: identidade e realidade. In: Cortelletti IA, Casara MB, Herédia
VBM, organizadores. Idoso asilado: um estudo gerontológico. Caxias do Sul, RS: Educs/Edipucrs; 2004. p. 13-60.

25. Moser AM. Melhoria da qualidade de vida de idosos residentes em um asilo, por meio de atividades vivenciais programadas. [tese de doutorado]. São Paulo: Instituto de Psicologia, Programa de Pós-graduação em Psicologia Experimental da Universidade de São Paulo; 2005.

26. Faleiros NP, Justo JS. O idoso asilado: a subjetividade intramuros. Rev Bras Geriatr Gerontol 2007;10(3):327-37.

27. Resende MC, Bones VM, Souza IS, Guimarães NK. Rede de relações sociais e satisfação com a vida de adultos e idosos. Psicol Am Lat [periódico na Internet]. 2006 [acesso em 12 fev 2010];5. Disponível em: http://pepsic.bvsalud.org/scielo.php?script $=$ sci_ arttext\&pid=S1870-350X2006000100015\&lng $=$ pt\& nrm $=$ iso.

28. Nogueira EJ. Rede de relações sociais: um estudo transversal com homens e mulheres pertencentes a três grupos etários. [tese de doutorado]. Campinas, SP: Faculdade de Educação da Universidade de Campinas; 2001.

29. Erbolato RMPL. Suportes sociais na velhice: uma investigação preliminar. In: Anais do XIV Congresso Brasileiro de Geriatria e Gerontologia e III Encontro Nacional das Ligas de Geriatria e Gerontologia. 8-12 jun 2004; Salvador. Salvador: GERON; 2004. p.108.

30. Souza LK, Hutz CS. Relacionamentos pessoais e sociais: amizade entre adultos. Psicol Estud 2008;13(2):257-65.

31. Silva CA, Menezes MR, Santos ACPO, Carvalho LS, Barreiros EX. Relacionamento de amizade na instituição asilar. Rev Gaúcha Enferm 2006;27(2):274 -83. 